\title{
Margens da Poética/Poéticas da Margem:o comparatismo planetário como prática de resistência
}

\author{
Anselmo Peres Alós \\ Rita Terezinha Schmidt
}

RESUMO: o presente artigo discute os rumos da Literatura Comparada, compreendida como uma prática de resistência aos riscos da homogeneização cultural neste início de milênio. Ao articular a questão da liminaridade do conhecimento produzido em torno das práticas culturais do presente, argumenta-se aqui em favor da manutenção das investigações comparatistas como um locus privilegiado para o questionamento de idéias e conceitos fossilizados, tais como o valor, o cânone, o nacional $e$ o estrangeiro. Defende-se aqui uma ampliação das margens e dos limites da poética, no sentido de fortalecer os vínculos entre as discussões sobre fenômenos literários e culturais com as questões do presente, tais como o desenvolvimento sustentável, a alteridade planetária e a ética da solidariedade.

PALAVRAS-CHAVE: Literatura Comparada, valor, cânone, estrangeiro, desenvolvimento, alteridade, ética

1 Margens, Limites, Fronteiras: O Estado Da Arte Nos Estudos Comparatistas

Não sou, não penso, não encontro meus espíritos, pois tenho mais de um que compartilha meu corpo, senão multiplicando em mim os contra-exemplos e as contraverdades que sou.

(Jacques Derrida, "Circonfissão").

$O$ crítico deve tentar apreender totalmente e assumir a responsabilidade pelos passados não-ditos, não representados, que assombram o presente histórico. (Homi Bhabha, O Local da Cultura).

We want to suggest that literary study as a form of intellectual critique should be ethically motivated both in its pedagogical practice and in its institutional formation. (Charles Bernheimer, "The Anxieties of Comparison”).

De que maneiras as questões levantadas pela literatura comparada podem contribuir para que a Universidade amplie seu papel como pólo de construção de um mundo melhor em termos de uma educação que fomente princípios de cidadania e de direitos humanos, contribuindo para a participação nas lutas pela erradicação das exclusões, dos preconceitos e discriminações contra culturas, segmentos sociais e territórios geográficos relegados à subalternidade ou à condição de "outros"? Ou, de maneira mais sucinta: qual a relevância dos conhecimentos produzidos pelos estudos de literatura comparada em uma conjuntura na qual eqüidade, desenvolvimento sustentável, direitos humanos e conservacionismo ambiental são as palavras de ordem na busca por uma sociedade mais justa?

$\mathrm{Na}$ esteira dos estudos contemporâneos de literatura comparada, o caráter apriorístico do discurso literário vem sendo questionado, uma vez que, se a literatura é um discurso resultante de práticas sociais intersubjetivas, sua especificidade não passa de um jogo de convenções cristalizado em determinados momentos históricos. A noção de "literatura nacional" vem sendo avaliada atualmente em seus estritos vínculos com os processos de constituição das "comunidades imaginadas", termo que Benedict Anderson utilizou em Imagined Communities para descrever os processos históricos de constituição dos nacionalismos europeus no século XVIII (Anderson, 1989). Da mesma maneira que uma concepção essencialista da nação vem sendo problematizada, preceitos tais como o valor artístico dos artefatos

Organon, Porto Alegre, $n^{\circ}$ 47, julho-dezembro, 2009, p.129 - 145 
culturais, por grande tempo considerado qualidade intrínseca e indispensável aos textos literários, passa a ser visto como o resultado da interação de fatores intrínsecos $e$ extrínsecos, fatores estes que sempre incluem nuances políticas, refratando os interesses hegemônicos, marcados pro cruzamentos que envolvem o gênero, a raça, a classe e a sexualidade, entre outras questões. A partir do abalo sísmico produzido pelas diversas correntes do pensamento contemporâneo, a teoria literária passou a questionar e historicizar a genealogia de suas próprias categorias de análise, e a pretensão ao universalismo vem sendo abandonada em nome de uma reflexão sobre as condições históricas e contextuais em que seu próprio discurso é formulado. O projeto de uma "poética geral" e de uma "história da literatura universal" (já questionados, em alguns aspectos, desde os anos 50 por René Wellek) passa a ser problematizado e, em muitos momentos, dá espaço a uma percepção pós-disciplinar que vê a literatura como prática discursiva em permanente diálogo com outros processos de semiose cultural, "contaminada" (no sentido derrideano do termo) por outros campos de saber, e implicada em relações de poder.

É neste contexto que os estudos comparatistas ganham uma relevância estratégica. Tal como afirma Mary Louise Pratt em "Comparative Literature and Global Citizenship" ( BERNHEIMER, 1995. p. 5865)., é fundamental "to advance a concept of comparative literature as a site for powerful intellectual renewal in the study of literature and culture". Em tempos de diásporas e exílios transnacionais de escala planetária, produzidos por um sem-fim de conflitos étnico-raciais, pela intolerância religiosa e pelos novos fundamentalismos, a literatura comparada transforma-se em "an especially hospitable space for the cultivation of multilingualism, polyglossia, the arts of cultural mediation, deep cultural understanding, and genuinely global consciousness. It can develop these things both as scholarly endeavors and as new forms of cultural citizenship in a globalized world" (p. 62). Finalmente, Pratt conclui seu raciocínio afirmando que o desenvolvimento de perspectivas globais na compreensão dos fenômenos culturais e literários não implica em pensar que qualquer possa reivindicar o conhecimento por inteiro de todo o globo.

Os influxos provenientes das teorias feministas, dos estudos pós-coloniais e da filosofia pósestruturalista, entre outras correntes do pensamento crítico, têm contribuído para uma reformulação e um alargamento dos campos de atuação, dos objetos de estudo e dos métodos investigativos da literatura comparada. Os limites do comparatismo, questão presente na pauta dos debates desde os primeiros momentos do estabelecimento da disciplina, são uma vez mais problematizados, ocupando o centro das discussões. A principal diferença entre as discussões contemporâneas e as polêmicas do passado é a evidência de que vários dos conceitos mais sólidos do comparatismo, tais como os de "identidade cultural", "nação", "língua nacional" e "literariedade" passam a ser problematizados, uma vez que são colocados sob suspeita e encarados como construções historicamente marcadas, ou ainda, como ficções conceituais. Conseqüentemente, abrem-se fissuras teóricas que permitem vislumbrar o comprometimento de tais categorias de análise como estruturas acumpliciadas com as hegemonias intelectuais. A relativização dos processos de constituição dos cânones nacionais vem possibilitando a constituição de um espaço importante para grupos minoritários que deles se viram excluídos ao longo da história. Assumindo suas próprias vozes, e reivindicando tradições culturais próprias, esta nova geração de críticos literários e pensadores da cultura passam a lutar pela flexibilização dos parâmetros da história literária canônica, com vistas a abrir espaço para outros textos e para outros discursos. A crítica literária feminista, nas suas diferentes vertentes, tem dedicado esforços no sentido de realizar uma "arqueologia literária", recuperando a produção das mulheres deixadas à margem da historiografia literária "oficial", questionando assim os princípios falocêntricos implícitos na escrita dos cânones literários ${ }^{1}$. Por sua vez, o pensamento diaspórico de críticos como Edward Said, Gayatri C. Spivak, Stuart Hall e Homi K. Bhabha tem contribuído para o estabelecimento de um "terceiro espaço" para se pensar a história e as identidades culturais dos povos subalternizados, cujas culturas, muitas vezes, foram objetificadas pelo pensamento eurocêntrico, em um gesto interpretativo que reinstalou premissas do imperialismo e do colonialismo. $\mathrm{O}$ campo conceitual do pós-estruturalismo questiona o alcance da própria noção de "verdade" construída pela tradição filosófica ocidental, desestabilizando preceitos tidos como universais e imutáveis tanto no campo da filosofia quanto no de outras ciências humanas.

É fundamental a reflexão sobre as margens da poética - isto é, sobre os limites e fronteiras da teoria literária e do comparatismo - para compreender a produção contemporânea, perpassada por múltiplas marcas de alteridade. Por que é importante a produção de saberes comparatistas no mundo atual? Qual a relevância destes saberes, e de que maneiras eles se inserem na produção contemporânea do conhecimento? De que formas o estudo das alteridades nas tradições literárias não-européias contribuem na compreensão dos diálogos transnacionais? Que tipo de discussão pode ser articulada a partir da

\footnotetext{
${ }^{1}$ Um importante exemplo deste trabalho no contexto brasileiro é dado pelos dois volumes da antologia Escritoras Brasileiras do Século XIX, organizada por Zahidé Muzart (Florianópolis; Santa Cruz do Sul: Mulheres; EDUNISC, 2000), nos quais são resgatados dos arquivos esquecidos os nomes de mais de cem escritoras brasileiras deixadas à margem dos compêndios de historiografia literária brasileira.
} 
emergência de paradigmas de análise literária tais como o ecofeminismo e a ecocrítica em um momento histórico no qual a qualidade de vida em escala global, a erradicação das exclusões e a luta pelos direitos humanos encontram-se no centro dos debates intelectuais? Muitos intelectuais contemporâneos têm salientado o fato de que um dos limites mais insuperáveis da razão humanista ocidental diz respeito às maneiras pelas quais a modernidade lidou com as estruturas de alteridade e de diferença. Tal como pergunta Mary Louise Pratt, como eliminar, nos níveis epistemológico e político, as desigualdades sociais $^{2}$ ? Uma resposta (ainda que breve) para estas questões inclui a problematização dos saberes nas condições históricas contemporâneas, e a consciência de que os processos de significação cultural estão sempre contextualizados e determinados pela conjuntura histórica e ideológica de seu tempo. A tendência metadisciplinar da Literatura Comparada a caracteriza como um importante espaço intelectual para avançar nestas questões, posto que, desde seu nascimento, este campo de estudos manteve um permanente questionamento tanto de sua definição, do seu objeto e do seu método, quanto da própria necessidade de flexibilização da categoria "disciplina", posto o seu constante diálogo com a História, a Teoria e a Crítica Literárias, bem como com outras áreas do saber (COUTINHO, 2001). Entre as questões pungentes que constituem o campo de interesses dos comparatistas na contemporaneidade, podem ser elencadas as seguintes preocupações:

a) $\mathrm{O}$ avanço nas discussões teóricas sobre os limiares e limites da prática comparatista na contemporaneidade, a partir de eixos de investigação que abarquem as categorias de identidade e da diferença, dando conta dos seguintes desdobramentos: raça e etnia; gênero e sexualidade; classe e subalternidade; o nacional, o transnacional e o diaspórico.

b) A realização de estudos de corpus, destacando-se particularmente obras representativas das crises do presente evidenciadas pelo discurso teórico, dando particular destaque às travessias e aos trânsitos literários de espaços geográficos caracterizados por processos históricos à margem da modernidade ocidental, dando particular atenção às nações da América Latina, da África, da Ásia e do Oriente Médio.

c) A reflexão sobre a alteridade, tomada como princípio norteador da prática comparatista, possibilitando assim uma articulação de preceitos éticos, estéticos e políticos na produção de conhecimento sobre a literatura, tomada como uma prática social de significação/textualização dos elementos do presente. Cumpre ressaltar que a alteridade não é aqui entendida meramente como o conteúdo do enunciado textual, mas como a própria possibilidade da formulação dos discursos crítico $e$ literário.

d) A articulação da pesquisa em literatura comparada a uma reflexão de cunho "metacrítico" e "metateórico", destacando o papel do comparatismo na área das Ciências Humanas e as suas contribuições fundamentais para a compreensão das alteridades e para o estabelecimento de uma consciência e de uma cidadania planetárias, tomando como ponto de partida a compreensão da cultura do outro. Para Gayatri Spivak, a idéia das coletividades transnacionais que atravessam e/ou trespassam fronteiras, em especial quando sob os auspícios da literatura comparada, deveriam ser pensadas não em termos continentais, mundiais ou globais, mas sim em termos de uma planetaridade compartilhada por toda a humanidade. Spivak reinterpreta e reformula a noção de globalização ao contrastá-la com o termo planetaridade, enfatizando assim a alteridade e a humanidade do planeta, em oposição ao caráter de construção e artificialidade do globo. Esse novo termo (a "planetaridade") permite uma visão renovada dos processos econômicos e culturais do mundo contemporâneo, uma vez que o vocábulo "globalização" se encontra já desgastado. Spivak argumenta que enquanto a noção de "globo" remete para um constructo abstrato e artificial no qual ninguém vive, a idéia de "planeta" pertence a um outro sistema conceitual, no qual se enfatizam as diferente relações que nós, humanos, estabelecemos empiricamente com o lugar concreto em que habitamos:

The globe is on our computers. No one lives there. It allows us to think that we can aim to control it. The planet is in the species of alterity, belonging to another system; and yet we inhabit it, on loan. It is not really amenable to a neat contrast with the globe. I cannot say "the planet, on the other hand." When I invoke the planet, I think of the effort required to figure the (im)possibility of this underived intuition. (SPIVAK, 2003. p. 72).

\footnotetext{
${ }^{2}$ PRATT, Mary Louise. Los imaginarios planetarios. Conferência apresentada por ocasião do IX Congresso Internacional da ABRALIC, ocorrido em Porto Alegre, na UFRGS, em 2004.

Organon, Porto Alegre, nº 47, julho-dezembro, 2009, p.129 - 145 
A importância estratégica da Literatura Comparada para o desenvolvimento das ciências humanas articula-se no nível de reconhecimento internacional que o comparatismo vem obtendo no contexto mais amplo das ciências sociais e humanidades. Cabe mencionar aqui a Encyclopedia of Life Sustainable Systems (EOLSS), que está sendo desenvolvida pela UNESCO ${ }^{3}$. Planejada como um compêndio integrado on-line, a EOLSS-UNESCO (subdividida em vinte enciclopédias interdependentes, e abarcando praticamente todas as áreas do conhecimento) reservou um espaço privilegiado para a Literatura Comparada no volume dedicado às Ciências Sociais e Humanidades. Tal reconhecimento por parte de uma organização de porte internacional como a UNESCO sinaliza a importância que o comparatismo alcançou no contexto das humanidades.

Em tempos de globalização e de multiculturalismo, o Ensino Superior vem sendo mercantilizado, enquanto a diferença cultural é reduzida à forma de commodities no mercado das idéias, com vistas a integrar a economia global como valor de escambo a serviço do capital. Resgatar o compromisso da crítica cultural com o embate de idéias e com a problematização da cultura própria e da cultura alheia (CARVALHAL, 2003.) é uma questão estratégica neste sombrio iniciar de século, o qual ameaça as culturas minoritárias e/ou subalternizadas com a instrumentalização do ensino de línguas estrangeiras. É esquecido o fato de que, agregada à língua do outro, está uma cultura e um sistema conceitual que não pode ser negligenciado a partir de uma compreensão rasa dos processos de tradução cultural. Sob o mito da transparência dos processos de tradução cultural, esconde-se uma lógica perversa que obnubila as diferenças. Se, tal como afirma Susan Bassnet, todo processo de tradução cultural implica em uma perda e em um ganho, cumpre restituir a importância de se potencializar os ganhos e minimizar as perdas através do reconhecimento das alteridades (BASSNET, 1998).

Os debates contemporâneos sobre o papel da tradução ganham uma nova dimensão nos estudos comparatistas atuais. Se é verdade que uma das premissas dos comparatistas foi sempre a de "ler no original", a dinâmica sócio-cultural destes tempos de capitalismo global coloca o comparatista diante de um impasse: deve-se abrir mão da premissa da "leitura no original" em nome da urgência de se estudar e compreender as literaturas e sociedades de zonas mais remotas, cujas línguas foram mantidas à margem das hegemonias lingüístico-nacionais perpetuadas nos estudos literários? Como alternativa às hegemonias lingüísticas do francês, do inglês, do espanhol e do alemão, provenientes de uma geopolítica cultural eurocêntrica, é válido lançar mão de traduções para o estudo de textos literários provenientes das comunidades falantes de árabe, mandarim, bengali e japonês? Este projeto alinha-se com a perspectiva de Charles Bernheimer, no famoso "The Bernheimer Report, 1993: Comparative Literature at the Turn of The Century", no qual o comparatista suíço salienta que: "while the necessity and unique benefits of a deep knowledge of foreing languages continue to be stressed, the old hostilities toward translation should be mitigated. In fact, translation can well be seen as a paradigm for larger problems of understanding and interpretation across different discursive traditions" (In: BERNHEIMER, 1995. p. 44).

Argumentando que mesmo dentro da Europa existem línguas minoritárias, tais como o húngaro e o neerlandês, e que o eurocentrismo revela-se, na prática, como o reflexo da hegemonia de umas poucas línguas nacionais (em especial do inglês, do francês, do espanhol e do alemão), Bernheimer chega à conclusão de que talvez seja mais adequado, por hora, trabalhar criticamente com estes textos em tradução (mesmo que não se tenha competência lingüística para se "ler no original" e realizar um eventual cotejo com a tradução) do que negligenciar estas vozes historicamente marginalizadas e subalternizadas pelo fato de que estas chegam a nós através da mediatização dos processos de tradução lingüística. A importância de políticas para a preservação da diversidade e da heterogeneidade lingüística e cultural pode ser atestada pela preocupação da UNESCO em torno da questão nesta última década. No ano 2000, a UNESCO proclamou o dia 21 de fevereiro como o Dia Internacional da Língua Materna. Estima-se que mais da metade das aproximadamente 6.700 línguas faladas no mundo correm perigo de desaparecer no futuro. Atualmente, o ritmo de extinção das línguas é de uma rapidez assustadora: deixa-se de falar uma língua no planeta a cada quinze dias ${ }^{4}$. A cada língua perdida, perde-se também todo o imaginário cultural a ela referente. Pode-se ir mais além, afirmando-se que a cada língua perdida, as possibilidades epistemológicas da humanidade ficam mais pobres, pois cada sistema lingüístico encerra uma maneira singular de apreender o mundo, ao conceber suas categorias analíticas particulares para tornar o real inteligível. A relevância do problema e a urgência de se criar estratégias para a preservação da diversidade lingüística levou a UNESCO a escolher 2008 como o Ano Internacional dos Idiomas. Segundo o Diretor geral da UNESCO, Koichiro Matsuura, "longe de constituir um âmbito reservado às análises dos experts no assunto, as línguas são a medula da vida social, econômica e cultural; esse é o

\footnotetext{
${ }^{3}$ O Comitê Internacional designado pela UNESCO para a preparação dos artigos sobre Literatura Comparada foi, inicialmente, presidido por Tania Franco Carvalhal. Em 2006, motivada por problemas de saúde, Carvalhal abre mão da presidência do comitê, que é assumida pela Vice-Presidente, Lisa Block de Behar. Maiores informações disponíveis no site www.eolss.net.

${ }^{4}$ Fonte: www.unesco.org.br/cultura.
} 
significado do lema escolhido pela UNESCO para o Ano Internacional dos Idiomas: os idiomas contam",

A textualização dos deslocamentos transnacionais ganha um papel de destaque na produção literária contemporânea. Estes textos ${ }^{6}$, ao problematizarem o nacional e o transnacional, sinalizam para uma reflexão sobre o fato de que o universal é uma categoria que não consegue dar conta daquilo que pretende. Posto que o universal é desde sempre definido de modo relativo, dado que sua definição parte sempre de um contexto histórico e dos limites impostos pelas particularidades lingüístico-culturais que possibilitam sua enunciação, ele se configura como uma aporia. Tal como afirma Homi Bhabha, "o presente não pode mais ser encarado simplesmente como uma ruptura ou um vínculo com o passado e o futuro, não mais uma presença sincrônica: nossa autopresença mais imediata, nossa imagem pública, vem a ser revelada por suas descontinuidades, suas desigualdades, suas minorias" (1998, p. 23). Tais discussões não apenas deslocam e problematizam a compreensão de noções como "literatura", "identidade" e "valor estético", mas contribuem para uma discussão mais ampla sobre o universal e o particular, instaurando novas possibilidades éticas, as quais invocam a alteridade como conceito-chave na crítica cultural. Redimensionar os regimes de representação das comunidades humanas, preocupação comum à Literatura Comparada e aos Estudos Culturais neste início de século, é o primeiro passo para que se construam novas possibilidades de relacionamento no campo social. Em outras palavras, o papel do comparatismo no cenário atual dos estudos literários e culturais pode ser definido como $a$ consolidação de um campo disciplinar e de um saber/poder sobre a diferença cultural $7^{7}$. O entendimento da literatura como artefato cultural não pode ser mais confinado ao beletrismo em nome da defesa de parâmetros judicativos tais como a literariedade ou a imanência do valor estético. Pleiteia-se, pois, a inserção do objeto literário no campo mais amplo da antropologia, da história, da política e da geografia, contextualizando como prática textual e discursiva que legitima, atravessa e - muitas vezes - subverte os arranjos hegemônicos de poder na esfera cultural.

2 A Raison d'être da Práxis Compratista:Leituras e Desleituras Metodológicas

Teoria em grego quer dizer O ser em contemplação Cântico dos cânticos Quântico dos quânticos (Gilberto Gil, "Quanta”)

Um olhar para o pensamento contemporâneo, no qual mesclas e migrações conceituais estão a sustentar relações não familiares e mesmo audazes, extrapolando as fronteiras vigiadas do saber acadêmico, evidencia o quanto hoje a teoria se tornou um gênero híbrido, isto é, uma zona de trânsitos transdisciplinares. Os efeitos desse ethos teórico na prática crítica e interpretativa, que é o eixo basilar das Letras, nem sempre são satisfatórios, redundando, não raro, em bricolages excessivas, ou então, em uma abstração tal que só vem a acentuar a assustadora contradição entre o mundo das idéias e o mundo da ação, entre as condições de vida e as formas como legitimamos a nossa profissão. Em outras palavras, se por um lado a transdisciplinaridade, como prática institucional, está pautada na necessidade de integrar os saberes e verticalizar a superfície plana da fronteira disciplinar, por outro lado a sua redução ao procedimento metodológico de um pluralismo desprovido de comprometimento com a reflexividade do pensar e com o questionamento de suas operações ideológicas tende a esvaziar a conflitividade do político-ideológico que se inscreve nas práticas simbólicas e, nesse sentido, não contribui em nada para o avanço do conhecimento crítico. Pelo contrário, se acumplicia ao processo de neoliberalização do conhecimento e suas demandas de saberes funcionais à pragmática do mercado globalizante capitalista.

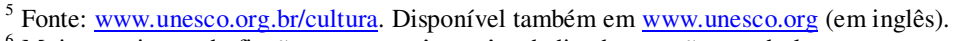

${ }^{6}$ Muito escritores de ficção contemporânea têm dedicado atenção aos deslocamentos transnacionais, lançando mão, muitas vezes, dos diários, das memórias e das reminiscências da diáspora, do exílio e do desterro. Tais narrativas, ademais de textualizarem a questão dos deslocamentos geográficos, abordam questões como os fundamentalismos religiosos, as fronteiras identitárias de gênero e raça e os ecos do colonialismo na contemporaneidade. Cabe citar, entre as narrativas mais recentes, as seguintes: ALI, Ayaan Hirshi. Infidel. London: Free Press, 2007; ALSANEA, Rajaa. Girls of Riyadh. New York: Penguin Press, 2005; BARGHOUTI, Mouri. Eu vi Ramallah. Rio de Janeiro: Casa da Palavra, 2006; FAQIR, Fadia. Meu nome é Salma. São Paulo: Agir, 2008; GHAHRAMANI, Zara. My Life as A Traitor. New York: Farrar, Straus and Giroux, 2007; MAATHAI, Wangari. Unbowed: A Memoir. New York: Knopf, 2006; NEMAT, Marina. Prisioner of Tehran: A Memoir. New York: Free Press, 2007; ONDAATJIE, Michael. Anil's Ghost. New York: Knopf, 2006 e COUTO, Mia. Remédios de Deus, Venenos do Diabo. Maputo: Ndjira, 2008.

${ }^{7}$ Com relação a estes debates contemporâneos do comparatismo, é de fundamental importância o volume organizado por Haun Saussy, intitulado Comparative Literature in An Age of Globalization (Baltimore: John Hopkins University Press, 2004).

Organon, Porto Alegre, $n^{\circ} 47$, julho-dezembro, 2009, p.129 - 145
} 
Substitui-se assim a figura do crítico/intelectual pela do profissional especialista que abdica do seu papel como mediador entre o mundo das idéias e o mundo da política real, das hegemonias e da violência, seja ela física ou simbólica.

É fundamental esclarecer que a crítica dirigida às práticas transdisciplinares no âmbito dos estudos literários não significa refutá-la em nome de uma apologia à diferença privilegiada da literatura e do valor estético, considerado isento das contingências e contradições que participaram, historicamente, de sua construção. A dissociação entre a vida e a arte é o efeito da ideologia humanista. Se a literatura existe para fazer sentido, socialmente falando, a ideologia do literário deve ser questionada e, para isso, a transdisciplinaridade abre caminhos altamente produtivos. A crítica a certas práticas nasce de uma reflexão que coloca sob suspeita o ecletismo ao mesmo tempo destituído de bases conceituais e descompromissado com o pensamento crítico conseqüente, o que facilmente pode ser tomado como uma estratégia de exclusão ética e política, ou seja, um conformismo que não passa de um efeito de subserviência ao status quo.

É pelos instrumentos disponibilizados pela teoria que se toma consciência de como o que se apresenta como realidade encontra-se sempre sob a intervenção de uma organização de significados, o que implica reconhecer o caráter discursivo do real-social, o papel de mediação da linguagem nas representações através das quais o ideológico se articula e atua como força política. É também a teoria que permite ao sujeito transformar uma determinada realidade dada como natural, abrindo os signos que a formulam a novas combinações interpretativas, capazes de refazer os trajetos conceituais (mesmo os implícitos) que ordenam sua compreensão. Em outras palavras, a teoria é inóspita à instrumentalização fácil das verdades administradas. Quando ela traduz, efetivamente, um ato crítico insurgente, comprometido com a intelecção da realidade, ela impõe um reposicionamento frente ao objeto de conhecimento que não tem nada de ingênuo, pois o questionamento das implicações políticas de um dado discurso levanta insistentemente a questão da responsabilidade ética, extensiva a toda expressão de saber articulado e veiculado dentro de um espaço considerado público.

O desafio intelectual colocado pelos movimentos históricos de lutas de independência e de direitos civis na década de 60, denunciando a ficção emancipatória da modernidade no desvelamento do racismo, do sexismo e do imperialismo subjacentes à política de edificação da cultura moderna no Ocidente, intensificou avanços teóricos afiliados ao processo que poderia se chamar de descolonização do conhecimento. Ao longo dos últimos trinta anos, os movimentos teóricos da desconstrução, do feminismo e do pós-colonialismo em suas críticas à hegemonia, seus deslocamentos dos lugares institucionalizados do saber/poder, seus questionamentos sobre a legitimidade de discursos fixos com pretensão de totalidade e universalidade têm processado a implosão das hierarquias definidas pelos limites disciplinares, promovendo outras formas de pensar e de saber o quadro crítico do campo social e intelectual configurado pela dinâmica da modernidade. Ao operarem com os conceitos de marginalidade, alteridade e diferença, o campo da teoria contemporânea deu visibilidade à condição de colonialidade dos sujeitos às margens, das minorias étnicas e raciais, das mulheres e dos homossexuais, e mesmo das nações emergentes, no sentido de um bloco definido como Terceiro Mundo. Entenda-se por colonialidade a permanência residual de mecanismos coloniais através de ajustes e transformações que permitem a sua reintegração e efetiva ação em um mundo em transformação. Isso significa dizer que a continuidade imperial no presente depende da dinâmica de variações de seu poder significativo como forma de atualizar-se e, assim, manter seu domínio. As perspectivas pós-coloniais e as teorias feministas dirigem o olhar do intelectual rumo a um questionamento das limitações geridas pelos consensos culturais, forçando a relativização e reformulação de categorias-chave do humanismo, tais como as de progresso e civilização, particularmente caras ao pensamento ocidental e às (meta)narrativas da modernidade.

Uma série de transformações profundas do conhecimento nas últimas décadas faz do tempo presente, particularmente na área das Humanidades, um momento extraordinariamente rico para elaborar novos modos de compreender os nossos objetos de estudo, de interpretá-los como produtos capazes de suscitarem questões de absoluta relevância - teórica, histórica, estética e ética - e de assim, problematizar a ordem da cultura como lugar de dissenso, de construção de identidades e sociabilidades nem sempre afiliativas, permeadas pela multiplicidade de vontades e poderes. Nas últimas décadas, o trânsito interdisciplinar permitiu conjugar saberes antes isolados por critérios normativos e molduras inflexíveis, fomentando um intenso debate intelectual sobre territórios constituídos e espaços institucionais tendo em vista o arquivo dos conhecimentos ocidentais e metropolitanos e as questões de poder implicadas em constelações conceituais, particularmente a partir de inserções políticas e geográficas específicas como a constituição das identidades das minorias e das sociedades periféricas do assim chamado Terceiro Mundo. Os influxos das reflexões marxistas na articulação dos novos estudos culturais (em particular naqueles de vertente britânica), os desdobramentos do feminismo e dos estudos de gênero que, por sua vez, possibilitaram a consolidação de novas frentes de reivindicação política na esfera cultural, tais como

Organon, Porto Alegre, no 47, julho-dezembro, 2009, p.129 - 145 
os queer studies ${ }^{8}$ e os estudos com relação à construção histórica da masculinidade, a resistência das teorias pós-coloniais aos discursos fossilizados sobre o papel histórico da modernidade nas culturas ocidentais e a valorização de categorias analíticas como raça e etnia na constituição de um novo objeto de estudo (definido como "branquitude"), são estas algumas das questões de alta voltagem crítica a atravessar, na contemporaneidade, as mais diferentes ciências alocadas sob o termo genérico de "Humanidades", produzindo novos saberes e funcionando como discursos de resistência ao mito da objetividade científica na produção de conhecimento sobre a literatura, as artes e a cultura.

Mesmo que o quadro da teoria contemporânea não se esgote nos desdobramentos apontados acima e que se reconheça nos seus discursos críticos a conjugação, não raro contraditória, de elementos conservadores e progressistas, o cenário permite constatar que a teoria está, mais do que nunca, direcionada para o que foi excluído pela "alta teoria" como processos de subjetivação, constituição de identidades e a natureza do político. Esse fato nos leva a pensar que a área das Humanidades está se redimensionando e se revitalizando, na medida em que seus discursos começam a se afastar de um certo diletantismo beletrista. Isso permite que se abale mitos como o do "valor literário", a ser demonstrados e comprovados por modalidades "politicamente neutras" de teoria e de crítica, isentas de maiores perquirições. Crer em uma "teoria ideologicamente neutra" implica em concordar com os interesses de uma elite, o que não deixa de ser uma opção ideológica ou, em última instância, uma prática política. Sendo o objeto dos estudos literários um constructo atravessado de historicidade (pois é constantemente redefinido), a estabilização do seu sentido torna-se um lugar privilegiado para a instauração daquilo que Bakhtin definiu como signo ideológico ou palavra ambivalente (BAKHTIN,1997).. Para Bakhtin, o signo não é apenas o material da luta ideológica, mas o próprio objeto de disputa: é no signo que se instauram os sentidos, configurando-se como a arena ideológica no qual os sentidos sociais (inclusive as posições hierárquicas que serão ocupadas pelos cidadãos) são disputadas. Logo, valor é um signo ideológico por natureza: definir (e legitimar a definição) de valor em se tratando de literatura significa legitimar uma cosmovisão de sociedade. Os critérios que definem o Belo são oriundos de uma posição discursiva que tem uma inserção de classe, de raça, de gênero e de orientação sexual clara e evidente: os universais são sempre declinados no masculino, na branquitude, na ótica burguesa e no imperialismo heterossexual.

\section{Literatura Comparada e Consciência Planetária: O Outro da Cultura e a Cultura Do Outro}

É muito razoável presumir que simples palavras não mudem a realidade. Mas as mudanças em nosso sistema conceitual realmente alteram o que é real para nós e afetam nossa percepção de mundo, assim como as ações que realizamos em função dessa percepção.

(Mark Johnson e John Lakoff, Metáforas da Vida Cotidiana).

O desenvolvimento das sociedades humanas em escala global pode ser caracterizado pela combinação de acelerados progressos materiais e científicos com o igualmente acelerado crescimento da pobreza, da iniqüidade e de diversas formas de violência, tanto concretas quanto simbólicas. Tais contradições aparentes podem ser "explicadas" a partir de dois paradigmas: o primeiro vê tal contexto como a conseqüência inevitável da natureza humana, cujo egoísmo estaria inclusive programado biologicamente como recurso para a sobrevivência da espécie; o segundo paradigma recusa-se a concordar com tal inevitabilidade, admitindo a possibilidade de que o progresso e a evolução podem ser administrados de modos racionais, com amplos ganhos para a sociedade como um todo.

De acordo com Ismail Sirageldin ${ }^{9}$, o final do século XX pode ser caracterizado por quatro forças motrizes a modelar o desenvolvimento humano, e que certamente se prolongam pelo século XXI. São elas o desenvolvimento científico, a formação de capital humano, a cultura, e os processos de globalização. Se é verdade que o desenvolvimento científico tem colaborado de maneira significativa para o desenvolvimento das comunidades humanas, também o é o fato de que tais avanços estão produzindo consequiências desastrosas ao ambiente, fomentando o aumento da pobreza e das desigualdades sociais. Neste sentido, faz-se urgente que as decisões técnicas e estratégicas em torno da distribuição de recursos e

\footnotetext{
${ }^{8}$ Conferir: THOMAS, Calvin (ed.) Straight with a Twist. Chicago: The University of Illinois Press, 2000. Ver também SEDGWICK, Eve Kosof sky. The Epistemology of The Closet. Berkeley: The University of California Press, 1990.

9 SIRAGELDIN, Ismail. SUSTEINABLE HUMAN DEVELOPMENT IN THE TWENTY-FIRST CENTURY: AN EVOLUTIONARY PERSPECTIVE. In: __. (Editor). Susteinable Human Development. [A book of Encyclopedia of Life Susteinable Systems (EOLSS), developed under the auspices of the UNESCO. EOLSS Publishers: Oxford (UK), 2003. Disponível em: http://www.eolss.net.
}

Organon, Porto Alegre, no 47, julho-dezembro, 2009, p.129 - 145 
oportunidades sejam realizadas através de imperativos éticos.

O desenvolvimento humano na contemporaneidade está embasado no avanço e na acumulação de conhecimento científico. Neste cenário, o papel da cultura, em especial dos seus aspectos de diversidade e adaptabilidade, fazem-se essenciais. Se, por um lado, os processos de globalização institucionalizaram a abertura das fronteiras e possibilitaram maior fluxo de informação transnacional, por outro eles fomentaram - como consequência reacionária e reativa - um aumento das sequelas resultantes dos choques culturais, tais como a violência e a intolerância. É mister salientar que algumas sociedades humanas rejeitam idéias pelo simples fatos de serem "estrangeiras", a despeito dos benefícios que poderiam catalisar.

Tal como Madame de Staël, que no início do século XIX introduz uma análise comparativa das literaturas e das artes alemãs na França com o livro De L'Allemagne (1810), o comparatista contemporâneo deve, antes de tudo, perguntar-se: "qual o propósito e a função social dos conhecimentos produzidos por minha atuação intelectual?". Uma vez que o par opositivo "cultura nacional vs. cultura estrangeira" continua a pautar conflitos tais como os novos fundamentalismos nacionalistas, os estudos de literatura comparada podem colaborar para minimizar os efeitos perniciosos dos choques culturais. Não é por acaso que filósofos como Jacques Derrida e Emmanuel Lévinas detiveram-se, nos últimos anos do século XX, a temas como a amizade, a solidariedade e a ética (DERRIDA, 1988; LÉVINAS, 1993).: estas são questões de suma importância para o desenvolvimento e o progresso científicos, de maneira sustentável, nestes tempos difíceis, encobertos pelas sombras e incertezas do presente. A partir do trabalho intelectual realizado pela literatura comparada é possível redimensionar e ressemantizar a noção de cosmopolitismo, em especial através do estudo e da reflexão acerca da literatura e da cultura estrangeiras, isto é, dos "outros", de forma a fazer da ética e da alteridade imperativos político-filosóficos para o novo milênio. Posto que o fluxo de informações em escala global torna inevitáveis os choques culturais, cumpre empreender esforços para que tais choques, dado que inevitáveis, tornem-se confrontos com resultados positivos e construtivos para as coletividades humanas do planeta.

Os estudos de literatura comparada lidam, antes de tudo, com palavras e com culturas, sejam estas próprias, sejam estas alheias. Se o insight de Johnson e Lakoff - apresentado na epígrafe seção - estiver correto, é o trabalho com as palavras e com as culturas o lugar privilegiado para que se possa avançar, construindo, a partir do trabalho intelectual, metáforas conceituais nas quais princípios como a ética, a alteridade, a solidariedade e a tolerância deixem de ser apenas substantivos abstratos, e passem a ser lidos como diretrizes, redimensionando assim as nossas ações no mundo. Uma vez que a hegemonia do Humanismo ocidental sobre as idéias, os valores e os conhecimentos é questionado, outra alternativa emerge: a de subsumir o discurso do humanismo ocidental em uma narrativa mais ampla, de alcance planetário. Isso não implica em uma proposta idealista, ou na afirmação ingênua da bondade intrínseca do gênero humano; trata-se simplesmente de minar as bases do etnocentrismo ocidental em nome do reconhecimento de outras genealogias culturais para noções como justiça social, direitos humanos, cidadania e ética. Dar ouvidos às vozes outras, localizadas tanto nas margens do capitalismo global quanto nos limiares das tradições do humanismo eurocêntrico, através do estudo, da reflexão e da produção de conhecimento das literaturas de regiões como a América Latina, a África, a Ásia e o Oriente Médio, configura-se como uma questão urgente e estratégica a colaborar para a construção de uma cidadania global e de uma consciência planetária.

\section{Bibliografia}

ALI, Ayaan Hirshi. Infidel. London: Free Press, 2007.

ALSANEA, Rajaa. Girls of Riyadh. New York: Penguin Press, 2005.

ANDERSON, Benedict. Nação e Consciência Nacional. São Paulo: Ática, 1989.

ARONA, M.; BeVERleY, J.; OVIEDO, J. (eds.) The Post-Modernism Debate in Latin America. Durham and London: Duke University Press, 1995.

BAKHTIN, M. Marxismo e Filosofia da Linguagem. 8 ed. São Paulo: Huicitec, 1997.

BARGHOUTI, Mouri. Eu vi Ramallah. Rio de Janeiro: Casa da Palavra, 2006.

BASSNET, S. Translation Studies. 4th Revised Edition. London: Routledge, 1998.

BELSEY, C. A Prática Crítica. Lisboa: Edições 70, [s.d.].

BENNINGTON, Geofferey and DERRIDA, Jacques. Jacques Derrida. Rio de Janeiro: Jorge Zahar, 1996.

BERNHEIMER, Charles. Comparative Literature in The Age of Multiculturalism. Baltimore: John Hopkins University Press, 1995.

Organon, Porto Alegre, no 47, julho-dezembro, 2009, p.129 - 145 
BHABHA, Homi K. O Local da Cultura. Belo Horizonte: UFMG, 1998.

BITTENCOURT, Gilda (organização). Transversões Comparatistas: Anais do I Colóquio Sul de Literatura Comparada. Porto Alegre: UFRGS, 2002.

BOONE, Joseph and CADDEN, Michael (editors). Engendering Men: The Question of Male Feminist Criticism. New York: Routledge, 1990.

BUTLER, Judith. Undoing Gender. London: Routledge, 2004.

CARVAlHAL, Tania Franco (org.) O Discurso Crítico na América Latina. Porto Alegre: IEL; UNISINOS, 1996.

COUTINHO. Eduardo (organização). Fronteiras Imaginadas: Cultura Nacional/Teoria Internacional. Rio de Janeiro: Aeroplano, 2001.

COUTO, Mia. Remédios de Deus, Venenos do Diabo. Maputo: Ndjira, 2008.

CULlER, Jonathan. Sobre a Desconstrução: Teoria e Crítica do Pós-Estruturalismo. Rio de Janeiro: Rosa dos Tempos, 1997.

DERRIDA, Jacques. A Escritura e a Diferença. São Paulo: Perspectiva, 1971.

DERRIDA, J. The Politics of Friendship. The Journal of Philosophy. Number 8, Nov. 1988.

FAQIR, Fadia. Meu nome é Salma. São Paulo: Agir, 2008.

GHAHRAMANI, Zara. My Life as A Traitor. New York: Farrar, Straus and Giroux, 2007.

HOLlandA, Heloísa Buarque de. Pós-Modernismo e Política. Rio de Janeiro: Rocco, 1992.

FOUCAULT, Michel. História da Sexualidade: A Vontade de Saber. 10 ed. São Paulo: Graal, 1988.

HOLLANDA, Heloísa Buarque de (org.) ¿Y nosotras latinoamericanas? Estudos sobre Gênero e Raça. São Paulo: Fundação Memorial da América Latina, 1992.

JAMESON, Fredric. O Inconsciente Político. Trad. Valter Lellis Siqueira. São Paulo: Ática, 1992.

LÉVINAS, E. Humanismo do Outro Homem. Petrópolis: Vozes, 1993.

MAATHAI, Wangari. Unbowed: A Memoir. New York: Knopf, 2006.

MAGGIE, Yvonne e REZENDE, Claudia Barcellos (organização). Raça como Retórica: A Construção da Diferença. Rio de Janeiro: Civilização Brasileira, 2002.

MCCLINTOCK, A.; MUFTI, A. and SHOAT, E. (editors). Dangerous Liaisons: Gender, Nation and Postcolonial Perspectives. Minneapolis: The University of Minnesota Press, 2004.

MIGNOLO, Walter. The Idea of Latin America. London: Blackwell Publishing, 2005.

MUZART, Zahide L. (Org.) Escritoras Brasileiras do Século XIX. 2 ed. Florianópolis; Santa Cruz do Sul: Mulheres; EDUNISC, 2000.

NEMAT, Marina. Prisioner of Tehran: A Memoir. New York: Free Press, 2007.

ONDAATJIE, Michael. Anil's Ghost. New York: Knopf, 2006.

PRATT, Mary Louise. Los imaginarios planetarios. Conferência apresentada por ocasião do IX Congresso Internacional da ABRALIC, ocorrido em Porto Alegre, na UFRGS, em 2004.

RUBIN, Gayle. The Traffic in Women: Notes on The "Political Economy" of Sex. In: REITER, Reyna (ed.). Toward an Anthropology of Women. New York: Monthly Review Press, 1975. p. 157-210.

SAID, Edward. Orientalismo. São Paulo: Companhia das Letras, 1990.

Cultura e Imperialismo. São Paulo: Companhia das Letras, 1995.

SAUSSY, Haun. Comparative Literature in An Age of Globalization. Baltimore: The John Hopkins University Press, 2006.

SEDGWICK, Eve Kosofsky. The Epistemology of The Closet. Berkeley: The University of California Press, 1990.

SIRAGELDIN, Ismail. Susteinable human development in the twenty-first century: an evolutionary perspective. In: ___ (Editor). Susteinable Human Development. [A book of Encyclopedia of Life Susteinable Systems (EOLSS), developed under the auspices of the UNESCO. EOLSS Publishers: Oxford (UK), 2003. Disponível em: http://www.eolss.net.

SPIVAK. Gayatri Chakravorty. Death of A Discipline. New York: Columbia University Press, 2003.

THOMAS, Calvin (ed.) Straight with a Twist. Chicago: The University of Illinois Press, 2000. 